\title{
Constraint analysis of dairy sector in North Eastern Region: A producers and consumers perspective
}

\author{
Ram Singh ${ }^{1}$, Singyala Chiphang ${ }^{1}$ and Ajmer Singh ${ }^{2}$
}

Received: 26 March 2021 / Accepted: 08 May 2021 / Published online: 27 July 2021

(C) Indian Dairy Association (India) 2021

\begin{abstract}
Livestock sector act as an alternative source of income for the rural population in the North East Region (NER) of India. But at the same time various limitations hinder the growth of this sector. So, the study was undertaken with the objective to examine the constraints faced by the dairy farmers and consumers of milk and milk products in the region. Assam and Meghalaya were selected purposively as these states were the leading states in cattle population in NER. A random sample of 110 dairy farmers and 174 consumers were selected for collecting primary data on constraints faced by them. The data analyzed using Garret's technique. The major constraints faced by the dairy farmers were the high cost of cattle feed and fodder, inadequate availability of green fodder, lack of organized set up for milk procurement and sale. For the consumers, the major constraints were adulteration, lack of desired quality and inadequate quality control along the value chain. Thus, efforts should be made from the government to take proper steps in regulating the feed prices. Additionally, efforts to set up quality control centre at the block/cluster level so that they can monitor the quality regularly which will further enhance the quality of milk and milk products which would help both the dairy farmers and consumers.
\end{abstract}

Keywords: Assam, Block, Cluster, Garret's ranking, Meghalaya

${ }^{1}$ School of Social Sciences, College of Post Graduate Studies in Agricultural Sciences, Central Agricultural University (Imphal), Umiam, Meghalaya, India

${ }^{2}$ DESM Division, ICAR-NDRI, Karnal, Haryana, India

Singyala Chiphang $(\bowtie)$

School of Social Sciences, College of Post Graduate Studies in Agricultural Sciences, Central Agricultural University (Imphal), Umiam, Meghalaya, India

Email: singyala@gmail.com
India is the world's largest milk producer producing 184.7 million metric ton (MT) of milk with the per capita availability of $394 \mathrm{gm} /$ day (NDDB, 2021). Though the country is self-sufficient in milk production there exist significant regional variation in milk production and in this regard, the North East Region (hereafter NER) is deficit in milk production. During 2018-19, the per capita availability of milk was only $71 \mathrm{gm} /$ day in Assam and $84 \mathrm{gm} /$ day in Meghalaya which are below all India average (NDDB, 2021). The growth of livestock sector has been found to be slower in the NER compared to the national level (Kumar et al. 2007) which may be attributed due to poor resource endowment in terms of number of crossbred, number of cooperatives, available marketing channels and other dairy infrastructures (Feroze et al, 2017).

Majority of the population in the NER belongs to small and marginal farmers. So far, the region is concerned the landless and marginal households keep livestock (NSSO, 2003). Livestock sector plays a vital role in economic activities for the landless and marginal households of the region. It also meets the nutritional requirement of the family (Athare et al. 2019).But significant advantages of this sectors from the point of view of demand arise for the livestock rearers from the fact that majority of the population in the NER prefer consumption of meat in their daily diet apart from consumption of milk and milk products.

However, there are number of constraints being faced by both the producers and the consumers. Evaluating the constraints will serve as one of the important tools for the policy making in the developmental activities of the dairy sector. So, the study has been carried out with an objective to evaluate the constraints faced by the dairy farmers and consumers of the NER.

The study was conducted in two states of the NER viz Assam and Meghalaya as these are the leading states in cattle population in the NER. From Assam, two districts were selected namely Kamrup (Metro) and Kamrup (Rural), from Meghalaya, Ri-bhoi district was selected. Six blocks were selected from two districts of Assam and one block from Meghalaya was selected. From the selected blocks of Assam, 14 villages were selected at random. From the selected block of Meghalaya, 2 villages were selected at random. A total 284 respondents were considered for the study 
of which 110 were dairy farmers and 174 were consumers. Data were collected using well-structured interview schedule.

To find out the constraints faced by the various stakeholders in production and consumption point of view in the study area, Garrett's ranking technique was applied. The constraints were prioritized by using the following formula:

Per cent Position $=\frac{100\left(R_{i j}-0.05\right)}{N_{j}}$

Where,

$R_{\mathrm{ij}}=$ Rank given for the $i^{\text {th }}$ item by $j^{\text {th }}$ respondent

$N_{j}=$ Number of items ranked by respondent

The percentage position of each rank was converted into scores using Garrett Table given by Garrette and Woodworth (1969). For each constraint, scores of individual respondents were added together and divided by total number of respondents for whom scores were added. Then, mean score for each constraint was ranked by arranging them in the descending order. Ranks were assigned and most important factors were identified.

Constraints refer to the problems faced by various stakeholders in carrying out various operations and management of various activities. It was observed that high input costs including feed and concentrate $(65.44 \%)$ was the major constraints for the dairy farmers in the study area (Table 1). This finding coincides with the findings of (Bhawar et al. 2020; Smitha et al. 2019; Lalrinsangpuii et al. 2016) in different states of India. The dairy farmers reported that during summer months there is shortage of green fodder so they have to compensate through other feed and concentrates, but majority of the farmers could not afford much as the prices of those feed and concentrates were high.

Inadequate availability of green fodder (63.20\%) was the second major constraint. This finding correlates with the finding of Rathod et al. (2009) in Karnataka that 91.66 per cent of the respondent reported non-availability of quality feed and fodder round the year. Similar finding was also reported by Smitha et al. (2019) in Kerala and Adhikari et al. (2020) in Uttarakhand. Since majority of the dairy farmers were landless farmers, they did not cultivate fodder crops separately, they depend on the common property resources for grazing animals and also for fodder collection (Feroze et al. 2017), so often there is shortage of green fodder especially during summer months. The dairy farmers in the study area do not grow fodder in their land purposively for livestock purpose. Grasses grown in the open fields and forest and crop residual viz., were used as green fodder and dry fodder for dairy purpose.

Lack of organized set up for milk procurement and sale (61.03\%) was also one of the major constraints. This finding coincides with the finding of Lalrinsangpuii et al. (2016) in Mizoram. The respondents from Meghalaya reported that since there were no other co-operatives apart from the existing one so it creates a problem in selling of milk. Most of them were forced to sell their milk in the existing co-operatives since there was not much option for them to dispose off their produce. Some of them further reported that the existing co-operatives were not functioning properly and failed to make the payment on time. About 60.71 per cent of the producer reported decreasing grazing area, long distance to reach the selling point $(58.22 \%)$, high transportation charges $(56.13 \%)$, lack of raw milk storage facility $(54.91 \%)$, occurrence of diseases and parasitic infection (54.07\%), nonremunerative price of milk and milk products $(50.95 \%)$, inadequate veterinary service $(50.33 \%)$, inadequate veterinary support

Table 1 Constraints faced by the dairy farmers in the NER

\begin{tabular}{lllc}
\hline Sl. No. & Particulars & Average Score & Rank \\
\hline 1 & High input costs including feed and concentrate & 65.44 & I \\
2 & Inadequate availability of green fodder & 63.20 & 61.03 \\
3 & Lack of organized set up for milk procurement and sale & 60.71 & II \\
4 & Decreasing grazing area & 58.22 & III \\
5 & Long distance to reach the selling point & 56.13 & IV \\
6 & High transportation charges & 54.91 & V \\
7 & Lack of raw milk storage facility & 54.07 & VI \\
8 & Occurrence of diseases and parasitic infection & 50.95 & VII \\
9 & Non remunerative price of milk and milk products & 50.33 & VIII \\
10 & Inadequate veterinary service & 49.98 & IX \\
11 & Inadequate veterinary support & 46.31 & X \\
12 & Delayed payment by vendors & 41.51 & XI \\
13 & Lack of labour & 23.23 & XII \\
14 & Effect of climatic change including extreme summer and winter & XIII & XIV \\
15 & Interference of local people & XV \\
\hline
\end{tabular}


Table 2 Constraints faced by consumer household in the NER

\begin{tabular}{lllc}
\hline Sl.No. & Particulars & Average Score & Rank \\
\hline 1 & Adulteration & 66.71 & I \\
2 & Lack of desired quality & 60.22 & II \\
3 & Inadequate quality control & 60.21 & III \\
4 & Non-availability of desired products & 53.78 & IV \\
5 & Fluctuating price of milk and milk products (MMPs) & 52.72 & V \\
6 & Cheating in quantity & 46.91 & VI \\
7 & Poor packaging & 46.07 & VII \\
8 & Expiry items with wrong label & 44.14 & VIII \\
9 & Timely supply & 38.05 & IX \\
10 & Affordability & 29.50 & X \\
\hline
\end{tabular}

(49.98\%), delayed payment by vendors (46.31\%), lack of labour (41.51\%), effect of climatic change including extreme summer and winter (23.23\%) and interference of local people (20.04\%).

It was observed that majority of the consumers i.e., 66.71 per cent were facing adulteration as the major constraint (Table 2). This may be due to the fact that most of the respondents were taking milk from the milk vendors and reported that the milk was adulterated by adding water.

About 60.22 per cent of the respondents reported that lack of desired quality was the second major constraint. As most of the respondent were availing milk through informal channel i.e. vendors, so getting a quality product is a great matter of challenge. About 60.21 per cent of the consumers reported lack of quality control. The consumers reported lacking of quality control right from milk producer level. Further reported, that sometimes the milk gets spoiled easily. This may be due to lack of hygiene during milking and handling process. The non-availability of desired products $(53.78 \%)$ is also one of the major constraints in the study area. The consumers were willing to get pay for the quality products but they are not getting the quality that they desired for. Fluctuating price of milk and milk products $(52.72 \%)$ is also one of the major constraints. Lalrinsangpuii et al. (2016) reported the similar finding in Mizoram. Frequent fluctuation in milk price may be due to change in various input cost. Frequent fluctuation in price of milk and its products caused a lot of problems for the consumers as milk is one of the basic necessities which are needed for every day's diet.

Other constraints include cheating in quantity $(46.91 \%)$, poor packaging $(46.07 \%)$, out-dated or expiry items with wrong label (44.14\%) followed by timely supply $(38.05 \%)$ and affordability $(29.50 \%)$.

\section{Conclusions}

The study concluded that the high input costs of feed \&fodder and adulteration were the major challenges faced by the dairy farmers and the consumers in the NER. So, it is recommended that government must take proper steps in regulating the prices for the feed and concentrate and also an effort to set up quality control centre at the block level so that they can monitor it regularly which will enhance the quality of milk and milk products.

\section{Acknowledgement}

The paper is derived from the ongoing CAU-NDRI collaborative project entitled "Estimation of production and utilization pattern of milk and milk products in India". The authors are thankful to the Central Agricultural University, Imphal and ICAR-NDRI, Karnal for making the collaboration and implementing this project.

\section{References}

Adhikari B, Chauhan A, Bhardwaj N, Kameswari VLV (2020) Constraints faced by dairy farmers in hill region of Uttarakhand. Indian J Dairy Sci 73(5):464-470

Athare PG, Verma A, Malhotra R, Sendhil R (2019) Economics of milk production in Pune district of Maharashtra: A comparative analysis. Indian J Dairy Science 72: 652-658.

Kumar A, Staal S, Elumalai K, Singh DK (2007) Livestock Sector in North- Eastern Region of India: An Appraisal of Performance. Agric Econ Res Rev 20:255-272

Bhawar RS, Dixit PK, Sivaram, M (2020) Constraints faced by the dairy farmers in production and marketing of milk in northern dry zone of Karnataka. Indian J Dairy Sci 73:274-279.https://doi.org/ 10.33785/IJDS.2020.v73i03.014

Feroze, SM, Singh, R, Sirohi S (2017) Fodder and labour for augmenting milk production in hills: A case study of Meghalaya. Indian J Dairy Sci 70: 611-615

Garrette, HE, Woodworth, RS (1969) The significance of the difference between means and other statistics. Statistics in Psychology and Education (New York: David Mckay Co. Inc., 1996): 228

Lalrinsangpuii, Malhotra R, Priscilla (2016) Economics of milk production and its constraints in Mizoram. Indian J Dairy Sci 69:588-594

NDDB (2021). NDDB statistics, NDDB, Anand, India. Accessed from https:/www.nddb.coop/information/stats/milkprodindia.

NSSO. (2003) Unit level data on land and livestock holdings (59th Round). National Sample Survey Office. Ministry of Statistics and Programme Implementation, Government of India, New Delhi

Rathod PK, Langde S, Nikam TR, Vajreshwari S (2009) Socio-personal profile and constraints of dairy farmers. Karnataka J Agric Sci 24: 619-621

Smitha, S, Devi MCA, Letha DG, Subhas S (2019) Analysis of constraints in dairy farming in Kerala-multistakeholder perspective. Indian $\mathrm{J}$ Dairy Sci 72: 342-346. doi.org/10.33785/IJDS.2019.v72i03.016 